\title{
GINCANA SOBRE RESÍDUOS \\ SÓLIDOS NA AULA DE GEOGRAFIA
}

\author{
Areli da Silva Andrade ${ }^{1}$ \\ Thais Emanuelle Monteiro dos Santos Souza² \\ Walma Nogueira Ramos Guimarães ${ }^{3}$
}

Resumo: As consequências do descarte irregular dos resíduos sólidos é um assunto de grande importância, pois afeta a vida de todos os seres vivos. O presente trabalho aborda o estudo da temática resíduos sólidos nas aulas de Geografia. O objetivo foi desenvolver uma gincana que buscasse sensibilizar os educandos para o descarte consciente dos resíduos sólidos durante as aulas de geografia, ao estudar os conceitos de paisagem e lugar. Foi feito uma pesquisa qualitativa, de análise direta e bibliográfica para o desenvolvimento da gincana como produto educacional. O produto desenvolvido foi validado por educadores de diversas áreas e através dele espera-se a formação de educandos mais responsável em relação as suas ações no ambiente.

Palavras-chave: Resíduos Sólidos; Gincana; Geografia; Educação Ambiental.

Abstract: The consequences of the irregular disposal of solid waste is a matter of great importance as it affects the lives of all living beings. This work deals with the study of solid waste in Geography classes. The objective was to develop a gymkhana that sought to sensitize students to the conscious disposal of solid waste during geography classes, when studying the concepts of landscape and place. Qualitative research, direct and bibliographic analysis was carried out to develop the gymkhana as an educational product. The developed product was validated by educators from different areas and through it is expected to train more responsible students in relation to their actions in the environment.

Keywords: Solid Waste; Gymkhana; Geography; Environmental Education.

\footnotetext{
1 Universidade Federal de Pernambuco. E-mail: silvaareli@hotmail.com, link para o Lattes: http://lattes.cnpq.br/1989979402983813

2 Universidade Federal de Pernambuco. E-mail: thaisemanuelle@hotmail.com, link para o Lattes: http://lattes.cnpq.br/3439916789810831

3 Universidade Federal de Pernambuco. E-mail: walmalamo@gmail.com link para o Lattes: http://lattes.cnpq.br/0134567530160247
} 


\section{Introdução}

Temas relacionados à Educação Ambiental vêm sendo abordados constantemente nos telejornais, comerciais e em eventos, mostrando como o ser humano vem interferindo no meio ambiente.

O ser humano vem transformando seu espaço e essas transformações geram impactos na vida da sociedade e na natureza. Scarlato e Pontin (1992, p.1) afirmam que "[...] o mundo mudou tanto para melhor como para pior: de um lado trazendo conforto, de outro deteriorando o meio ambiente". Muitas dessas transformações trouxeram benefícios para a sociedade, tornando a vida mais confortável, mas também trouxeram problemas, como é o caso dos resíduos sólidos que a sociedade moderna produz, por isso a importância de trabalhar essa temática nas escolas.

A escola é um espaço de aprendizagens. Dentre as diversas disciplinas que compõem a grade curricular dos educandos, embora a Educação Ambiental não seja de responsabilidade de uma única disciplina, a geografia por ser uma ciência que estuda o espaço construído pelo ser humano, oferece muitas possibilidades para se trabalhar a temática ambiental durante suas aulas. A geografia pode contribuir para a Educação Ambiental ao "fornecer instrumentos para que os cidadãos possam localizar os diferentes ambientes produzidos pelo homem e outros por ele preservados ou destruídos e compreender os significados dessa localização" (CAVALCANTI, 2002, p 17,18).

Tudo que envolve melhorar a relação homem e natureza requer mudança de comportamento, e essa mudança é lenta e conflitante. Para que haja um resultado positivo é necessário escolher bem a modalidade didática utilizada durante o processo de ensino e aprendizagem, pois ela deve levar os envolvidos a quererem as mudanças que estão sendo propostas.

Diante disso, a gincana aqui apresentada é um produto educacional, fruto do trabalho de dissertação que teve como objetivo desenvolver, durante as aulas de geografia, ao estudar os conceitos de paisagem e lugar, uma gincana que buscasse sensibilizar os educandos para o descarte consciente dos resíduos sólidos.

$\mathrm{Na}$ gincana, os resíduos sólidos assumem papel de destaque durante o estudo dos conceitos geográficos de paisagem e lugar levando o educando a perceber a interferência humana no meio ambiente, e o quanto o ser humano tem prejudicado o seu próprio habitat lançando de forma irregular os resíduos sólidos no espaço geográfico. 


\section{A Educação Ambiental e a Geografia}

A escola é um espaço onde o desenvolvimento do conhecimento está presente, "é um lugar de encontro de culturas, de saberes, de saberes científicos e de saberes cotidianos, ainda que o seu trabalho tenha como referência básica os saberes científicos". (CAVALCANTI, 2002, p.33). Este local possui uma grande importância para a sociedade pois "[...] a população, [...] procura a escola para suprir as necessidades de estudo e aprendizagem" (KIMURA, 2010, p.70). A escola é um espaço reconhecido pela sociedade, como o local onde se adquire o conhecimento, "a escola é, sem dúvida, o melhor canal de conscientização, pois ela é responsável pela educação do indivíduo e, consequentemente, da sociedade, e é por meio de indivíduos bem informados que se podem tomar as devidas decisões" (SILVA; SOUZA, 2015, p.311).

Porém a escola é um espaço que produz não apenas conhecimento, mas também resíduos sólidos. A forma como os educandos agem diante dos resíduos sólidos que geram ficam evidenciados no dia-dia do espaço escolar. O educando descuidado com o descarte do seu resíduo sólido no ambiente escolar, onde este tem acesso a cestos de lixo, também terá o mesmo comportamento ao andar pela cidade. "É na escola onde se darão as maneiras como as pessoas irão interagir segundo algumas circunstâncias" (KIMURA, 2010, p.59). A Educação Ambiental pode contribuir para mudar esse cenário.

A Educação Ambiental se constitui como um instrumento, capaz de sensibilizar a comunidade escolar, e fazer com que os alunos se tornem seres conscientes e críticos em relação ao meio ambiente, principalmente quando o problema está associado ao gerenciamento dos resíduos sólidos escolares. (SANTOS; COSTA; SANTOS, 2019, p. 28)

Por isso, a escola é um bom lugar para o desenvolvimento de um ensino que busque trabalhar as questões ambientais, colaborando para a formação de cidadãos mais responsáveis com o meio ambiente.

Quando comparado as demais disciplinas escolares, a Educação Ambiental pode ser considerada uma novidade no ambiente escolar. É somente a partir da década de 1970, que a questão ambiental se torna mais forte. Como lembra Cascino (2003, p.40) "o homem do final da década de 60 reconhecia-se como agente transformador/destruidor das coisas sociais e naturais, pois esse mesmo homem procurava ser consciente dos limites naturais e sociais". No Brasil, a preocupação com as questões ambientais vem aparecer na Constituição de 1988. 
Todos têm direito ao meio ambiente ecologicamente equilibrado, bem de uso comum do povo e essencial à sadia qualidade de vida, impondo-se ao Poder Público e à coletividade o dever de defendê-lo e preservá-lo para as presentes e futuras gerações. (BRASIL, 1988 art. 225).

Apesar do artigo 225, da constituição estabelecer de forma clara os direitos e deveres do cidadão em relação ao meio ambiente, muitos dos educadores de hoje, e sociedade de modo geral, não aprenderam a conservar o ambiente para as gerações futuras. Trata-se de uma geração que não recebeu Educação Ambiental tendo que ensinar a outra que é necessário conservar o meio.

Para que o educando possa ser mais ativo em relação a preservação ambiental é necessário que ele se veja como parte do ambiente, e compreenda suas ações no espaço, e a geografia pode contribuir para que isso ocorra.

Para a geografia, o ambiente é resultado das interações que ocorrem nele "a sua construção se dá no jogo entre poderes, interesses e práticas da sociedade com a natureza e com os objetos naturais" (CAVALCANTI, 2002, p. 17). O entendimento de que os fatores sociais e naturais formam o ambiente é importante para a compreensão de que as ações humanas sobre o espaço devem ser bem pensadas e planejadas, pois a humanidade e a natureza estão interligadas.

O estudo dos conceitos geográficos de paisagem e lugar oferece condições para o ensino acerca dos resíduos sólidos, pois eles estão presentes nas paisagens que compõe o lugar.

É no lugar que os problemas causados pelos resíduos sólidos aparecem e afetam a vida dos seres vivos. Layrargues (2011, p. 185) fala que "a questão do lixo vem sendo apontada pelos ambientalistas como um dos mais graves problemas ambientais urbanos da atualidade", porém para que os educandos compreendam essa situação é necessário que eles vejam como os resíduos sólidos afetam o seu lugar e o mundo. Os problemas ambientais e sociais causados pelos resíduos sólidos não afetam apenas o lugar de vivência, mas também outros lugares e suas paisagens.

A paisagem não é estática, ela está em constante transformação. Através da paisagem é possível compreender quem vive num lugar, quais são seus hábitos, sua história, os recursos que dispõe, como também os resíduos sólidos que gera e como são descartados. Conforme Puntel (2007), o estudo da paisagem possibilita o desenvolvimento de atitudes, valores e normas básicas que contribui para a formação do cidadão. Por esta razão o estudo da paisagem pode contribuir para a formação de cidadãos mais responsáveis com a questão do descarte dos seus resíduos sólidos.

Os conceitos de paisagem e lugar estão relacionados entre si, pois vão 
nesse espaço que está em constante transformação. O estudo dos resíduos sólidos junto com os conceitos de paisagem e lugar, ajudarão os educandos a compreenderem melhor seu espaço e os impactos dos resíduos sólidos provocados no ambiente.

\section{O Lúdico na Educação Ambiental}

As formas de ensinar ao longo do tempo foram se transformando. Hoje o ensino não se apresenta apenas na forma tradicional, onde são empregados o livro e quadro para se trabalhar um assunto. A disposição da educação, além dos materiais tradicionais, também se tem os equipamentos tecnológicos e as atividades lúdicas.

Em relação as atividades lúdicas, elas são importantes para o processo educativo porque "são atividades que podem constituir-se em uma grande estratégia didática, facilitando a adesão dos alunos" (KIMURA, 2010, p.150). Com o desenvolvimento de atividades lúdicas, as aulas se tornam mais convidativas para os educandos, aproximando-os de saberes que antes podiam considerar complexos.

Aprender brincando é prazeroso e estimulante, faz-nos compreender conceitos, cálculos, entre outros, de forma lúdica. Ludicidade nos ensina a trazer alegria e enriquece a gama de conhecimentos que o aluno conquista através de jogos e brincadeiras (BRANCO; MOUTINHO, 2015, p. 2201.2).

Através da atividade lúdica também é possível que os educandos tenham uma melhor compreensão dos novos conceitos que o educador estiver trabalhando. Kimura (2010) ressalta que por trás de uma atividade lúdica pode haver um conceito sendo trabalhado. Câmara (2017) nos lembra que "ensinar ludicamente é induzir à motivação e à diversão, pois tal atitude representa liberdade de expressão, a renovação e a criação do ser humano".

Atividades lúdicas envolvem brincadeiras e jogos, que despertam o interesse pelos temas trabalhados, estimulando assim o desejo de aprender, melhorando o processo ensino-aprendizagem.

Quando uma pessoa é submetida a uma situação problema que está presente nos jogos ou desafios, estes favorecem sua concentração, o trabalho em grupo, sua atenção, o seu engajamento e a imaginação, e consequentemente irá estimular a pessoa a buscar soluções para os desafios que a atividade apresenta (BRANCO; MOUTINHO, 2015, p. 2201.2). 
Dentre os tipos de atividades lúdicas, a gincana, por se tratar de uma competição, estimula a criatividade dos educandos, desenvolve habilidades para trabalhar em grupo, e os ajuda a tomar decisões, habilidades necessárias para a formação de cidadãos responsáveis com as questões ambientais. Como a Educação Ambiental envolve mudança de atitude e valores, muitos considerados normais pela sociedade, trabalhar de forma lúdica ajuda a consolidação de novos hábitos.

\section{Metodologia}

Esta pesquisa foi realizada em uma escola municipal localizada no município de Gravatá - PE, onde foi feita uma pesquisa qualitativa, de análise direta. Inicialmente foi utilizado o método observacional para compreender como era feito o descarte dos resíduos sólidos na escola visto que esta já possui coleta seletiva, em seguida foram realizadas entrevistas não padronizadas com educandos do 6ํㅜㄹ ano do Ensino Fundamental, público para o qual se destina o produto educacional desenvolvido.

Também foram realizadas pesquisas bibliográficas em livros e artigos, com o objetivo de verificar como a temática dos resíduos sólidos era trabalhada de forma lúdica; como os conceitos geográficos de paisagem e lugar poderiam contribuir para o estudo dos resíduos sólidos e como a geografia poderia contribuir com a Educação Ambiental. A partir das informações coletadas obteve-se dados que orientaram a formulação de uma gincana.

A elaboração da gincana foi dividida em três etapas. Na primeira etapa foram elaboradas as tarefas que seriam realizadas e a construção da sequência didática que acompanha a gincana. A segunda etapa consistiu na elaboração das regras e pontuações que variaram de acordo com a atividade proposta. Também foi desenvolvido um quadro onde constam as atividades, os critérios de avaliação, data de entrega, além da pontuação que determinará qual equipe será a vencedora da gincana.

A terceira parte da elaboração da gincana envolveu o seu encerramento. Embora a gincana tenha sido desenvolvida para ser vivenciada no 6o ano do ensino fundamental, ela também buscou sensibilizar toda escola para a questão dos resíduos sólidos, para isso, no seu encerramento as atividades desenvolvidas pelos educandos do $6^{\circ}$ ano são expostas para todos que compõe a escola. As duas últimas tarefas também são apresentadas no encerramento da gincana, tudo com o objetivo de sensibilizar os demais educandos para a necessidade do descarte correto dos resíduos sólidos. Após a apresentação das duas últimas tarefas, tem a divulgação do resultado da gincana e premiação, que pode ser composta por medalhas ou certificados de participação. 


\section{A Gincana}

O produto desenvolvido, intitulado "A Gincana Invadiu a Aula de Geografia" foi pensado para turmas do 60 ano, houve a preocupação de buscar atividades que estivessem de acordo com desenvolvimento cognitivo e realidade dos educandos. A experiência na realização de gincanas no ambiente escolar contribuiu para a seleção das atividades.

As tarefas da gincana buscam levar os educandos a pensarem sobre seu espaço com um olhar ambiental. Verri e Endlich (2009), demonstram que quando o jogo é usado como recurso pedagógico o processo de ensinoaprendizagem se torna mais prazeroso para o educando. A gincana possui um total de seis encontros, sendo o último voltado para o seu encerramento. Para os cinco primeiros encontros foram desenvolvidas algumas atividades para os educandos desenvolverem (Quadro 1).

Quadro 1: Atividades do Produto Educacional: A Gincana Invadiu a Aula de geografia

\begin{tabular}{|l|l|l|}
\hline Encontros & Tema da Aula & Atividade da Gincana \\
\hline 01 & $\begin{array}{l}\text { O que é } \\
\text { Paisagem? }\end{array}$ & $\begin{array}{l}\text { Fazer um pequeno texto descrevendo a paisagem que } \\
\text { você ver da porta de sua casa. O texto deverá ter no } \\
\text { mínimo cinco linhas e no máximo dez. }\end{array}$ \\
\hline 02 & $\begin{array}{l}\text { Paisagem: um } \\
\text { espaço em } \\
\text { movimento }\end{array}$ & $\begin{array}{l}\text { Você também é um agente transformador da paisagem. } \\
\text { Que tal reduzir a quantidade de resíduos que geramos? } \\
\text { Transforme garrafa pet, caixa de papel, isopor ou qualquer } \\
\text { outro material que seria descartado em um brinquedo ou } \\
\text { objeto de utilidade para casa e apresente na próxima aula. } \\
\text { O grupo deverá apresentar apenas um produto. }\end{array}$ \\
\hline 03 & O Lugar & $\begin{array}{l}\text { Fotografar pontos da cidade onde o descarte do resíduo } \\
\text { sólido foi feito de forma irregular e criar um cartaz com } \\
\text { elas. Identifique a foto colocando o local, data e hora. } \\
\text { Fotos retiradas da internet não serão aceitas. Crie um título } \\
\text { para o cartaz e faça uma pequena mensagem que reflita o } \\
\text { sentimento do grupo em relação ao lugar onde foram feitas } \\
\text { as fotos (o que você sentiu ao ver o seu lugar sujo). }\end{array}$ \\
\hline 04 & $\begin{array}{l}\text { Para onde vão os } \\
\text { resíduos sólidos? }\end{array}$ & $\begin{array}{l}\text { Criar um poema, com no mínimo quatro estrofes, contando } \\
\text { tudo que você aprendeu durante a visita ao Aterro } \\
\text { Sanitário e a Cooperativa de Catadores. }\end{array}$ \\
\hline 05 & $\begin{array}{l}\text { As atividades } \\
\text { realizadas no } \\
\text { lugar }\end{array}$ & $\begin{array}{l}\text { Apresentar uma proposta para minimizar o impacto dos } \\
\text { resíduos sólidos gerados pela atividade econômica no seu } \\
\text { lugar de vivência. }\end{array}$ \\
\hline
\end{tabular}

Fonte: Produto Educacional - A Gincana Invadiu a Aula de Geografia, 2020.

Todas as atividades foram pensadas para os educandos desenvolverem fora do espaço escolar, pois em Gravatá, as aulas de geografia para $\circ 6^{\circ}$ ano possui uma carga horária de 80 aulas, o que resulta em duas aulas semanais tornando inviável a realização das atividades da gincana no momento da aula.

Durante as semanas que acontecerá a gincana, os educandos estudarão os conceitos geográficos de paisagem e lugar dando enfoque para a 
questão dos resíduos sólidos, e ao final de cada aula terão uma tarefa da gincana relacionada ao que foi estudado.

De acordo com as regras da gincana, os educandos tem um prazo de uma semana para entregarem as atividades que foram propostas, com exceção para as atividades dos encontros 4 e 5 , pois essas serão apresentadas no encerramento da gincana.

Para melhor clareza sobre as regras e pontuações foi confeccionado um quadro para que o educador pudesse colocar a pontuação dos grupos e assim ao final estabelecer o vencedor. O Quadro 2 foi pensado para uma turma de 50 educandos, porém dependendo do quantitativo de educandos na turma 0 educador poderá diminuir a quantidade de grupos.

Quadro 2: Parte da pontuação da gincana.

\begin{tabular}{|c|c|c|c|c|c|}
\hline Tarefa & $\begin{array}{l}\text { Data de } \\
\text { entrega }\end{array}$ & $\begin{array}{l}\text { Participaçáo } \\
\text { de todos }\end{array}$ & Regras & $\begin{array}{c}\text { Pontuação } \\
\text { Máxima }\end{array}$ & $\begin{array}{l}\text { Pontuação } \\
\text { do grupo }\end{array}$ \\
\hline \multirow{10}{*}{$\begin{array}{l}\text { Escrever } \\
\text { um texto, } \\
\text { com no } \\
\text { mínimo } 5 \\
\text { linhas e no } \\
\text { máximo 10, } \\
\text { sobre a } \\
\text { paisagem } \\
\text { que se vê } \\
\text { da porta da } \\
\text { sua casa }\end{array}$} & & \multirow{10}{*}{$\begin{array}{l}(5,0) \text { Sim } \\
(2,0) \text { Não }\end{array}$} & $\begin{array}{l}\text { Tarefa entregue } \\
\text { dentro do prazo }\end{array}$ & \multirow{10}{*}{. } & G1 \\
\hline & & & $\begin{array}{l}(4,0) \text { Sim } \\
(1,0) \text { Não }\end{array}$ & & G2 \\
\hline & & & & & G3 \\
\hline & & & \multirow{4}{*}{$\begin{array}{l}\text { Coeréncia com } \\
\text { o que foi pedido } \\
(3,0) \text { Sim } \\
(1,0) \text { Parcial } \\
(0,0) \text { Não }\end{array}$} & & G4 \\
\hline & & & & & G5 \\
\hline & & & & & G6 \\
\hline & & & & & G7 \\
\hline & & & \multirow{3}{*}{\begin{tabular}{|lr} 
Respeitou & $\circ$ \\
número & de \\
linhas & \\
$(3,0)$ Sim & \\
$(0,0)$ Não &
\end{tabular}} & & G8 \\
\hline & & & & & G9 \\
\hline & & & & & G10 \\
\hline \multirow{10}{*}{$\begin{array}{l}\text { Criar } \\
\text { brinquedos } \\
\text { ou objetos } \\
\text { utilizando } \\
\text { materiais } \\
\text { que seriam } \\
\text { descartados }\end{array}$} & & \multirow{10}{*}{$\begin{array}{l}\text { (10) Sim } \\
(5,0) \text { Não }\end{array}$} & \multirow{4}{*}{$\begin{array}{l}\text { Tarefa entregue } \\
\text { dentro do prazo } \\
(5,0) \text { Sim } \\
(1,0) \text { Não } \\
\text { Reutilizou } \\
\text { materiais } \\
(5,0) \text { Sim } \\
(0,0) \text { Não }\end{array}$} & \multirow{10}{*}{25} & G1 \\
\hline & & & & & G2 \\
\hline & & & & & G3 \\
\hline & & & & & G4 \\
\hline & & & \multirow{4}{*}{$\begin{array}{l}\text { Funcionalidade } \\
\text { do material } \\
\text { produzido } \\
(2,5) \text { boa } \\
(1,5) \text { regular } \\
(0,0) \text { ruim }\end{array}$} & & G5 \\
\hline & & & & & G6 \\
\hline & & & & & G7 \\
\hline & & & & & G8 \\
\hline & & & \multirow{2}{*}{$\begin{array}{l}\text { Aparência } \\
(2,5) \text { boa } \\
(1,5) \text { regular } \\
(0,0) \text { ruim }\end{array}$} & & G9 \\
\hline & & & & & G10 \\
\hline
\end{tabular}

Fonte: Produto Educacional - A Gincana Invadiu a Aula de Geografia, 2020.

Além das aulas teóricas, também está previsto uma visita ao aterro sanitário e a uma cooperativa de reciclagem, pois é necessário que haja o entendimento do que acontece com os produtos após o seu descarte. 
Com o intuito de que a gincana não fosse o brincar pelo brincar, foi desenvolvida uma sequência didática para dar o suporte teórico aos educandos, levando-os a compreender o seu lugar, iniciando assim sua leitura do mundo numa perspectiva ambiental. Foram elaboradas atividades que estivessem próximas à realidade do educando. Crisostimo $(2011$, p. 89) chama à atenção para a "necessidade de uma educação que tenha como princípio o ambiente onde o ser humano está inserido".

Para separar as atividades desenvolvidas na sala de aula, das atividades da gincana foram desenvolvidas duas seções dentro da sequência didática. Na seção "Para guardar na Mente" foram colocadas as atividades que serão desenvolvidas em sala de aula. Já as atividades da gincana, foram organizadas na seção intitulada "Desafio da Semana" (Quadro 3).

Quadro 3: Trecho da sequência didática do encontro 1 da Gincana.

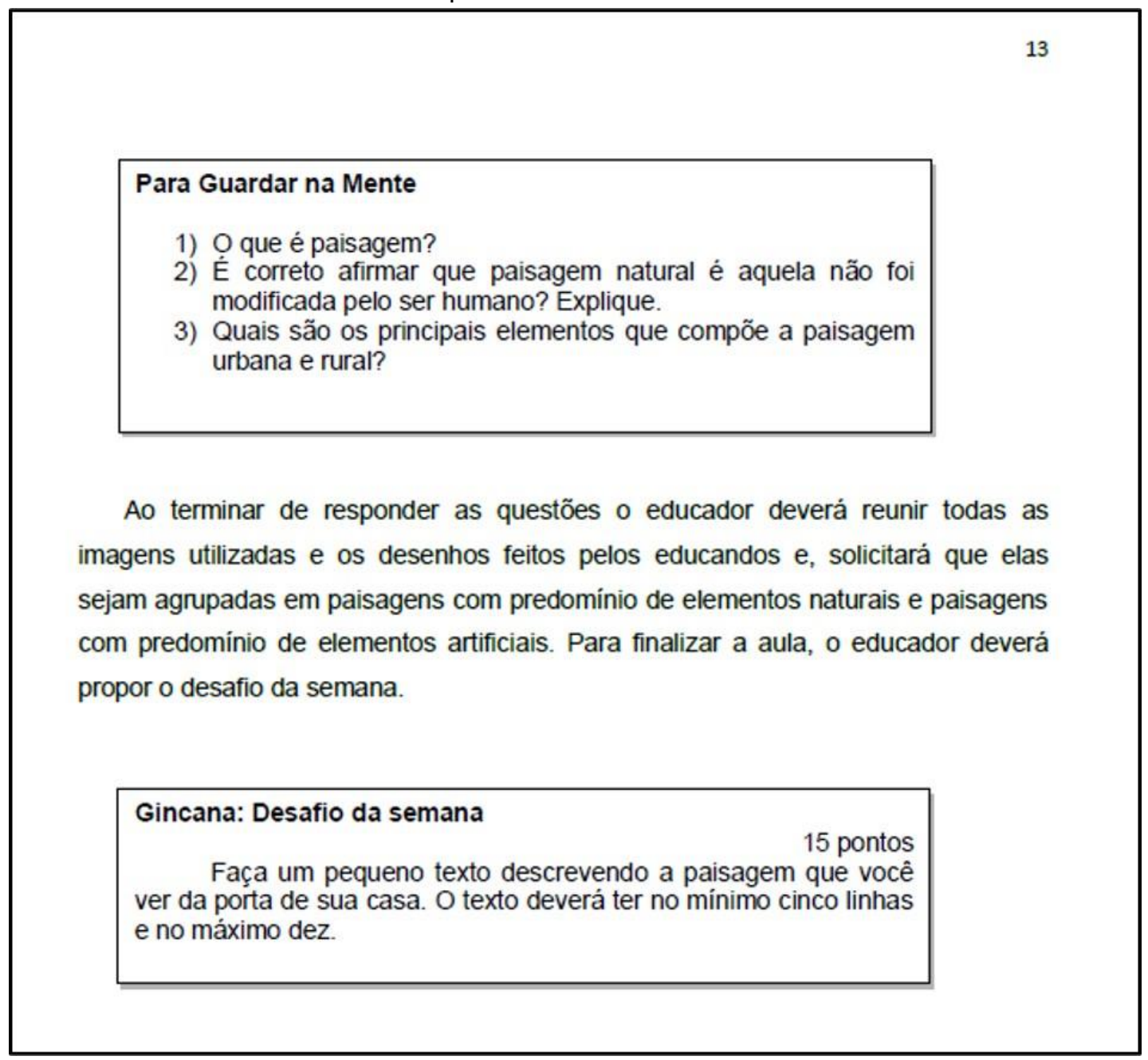

Fonte: Produto Educacional - A Gincana Invadiu a Aula de Geografia, 2020. 
A sequência didática também traz sugestão para trabalhar de forma interdisciplinar, pois a Educação Ambiental não é tarefa de uma única disciplina (BRANCO; ROYER; BRANCO, 2018). Sabendo disso, foi pensado em meios para integração das demais ciências, tanto nas aulas como na gincana, fortalecendo assim o processo de ensino e aprendizagem como pode ser visto na Quadro 4.

Quadro 4: Planejamento do encontro 3 da Gincana.

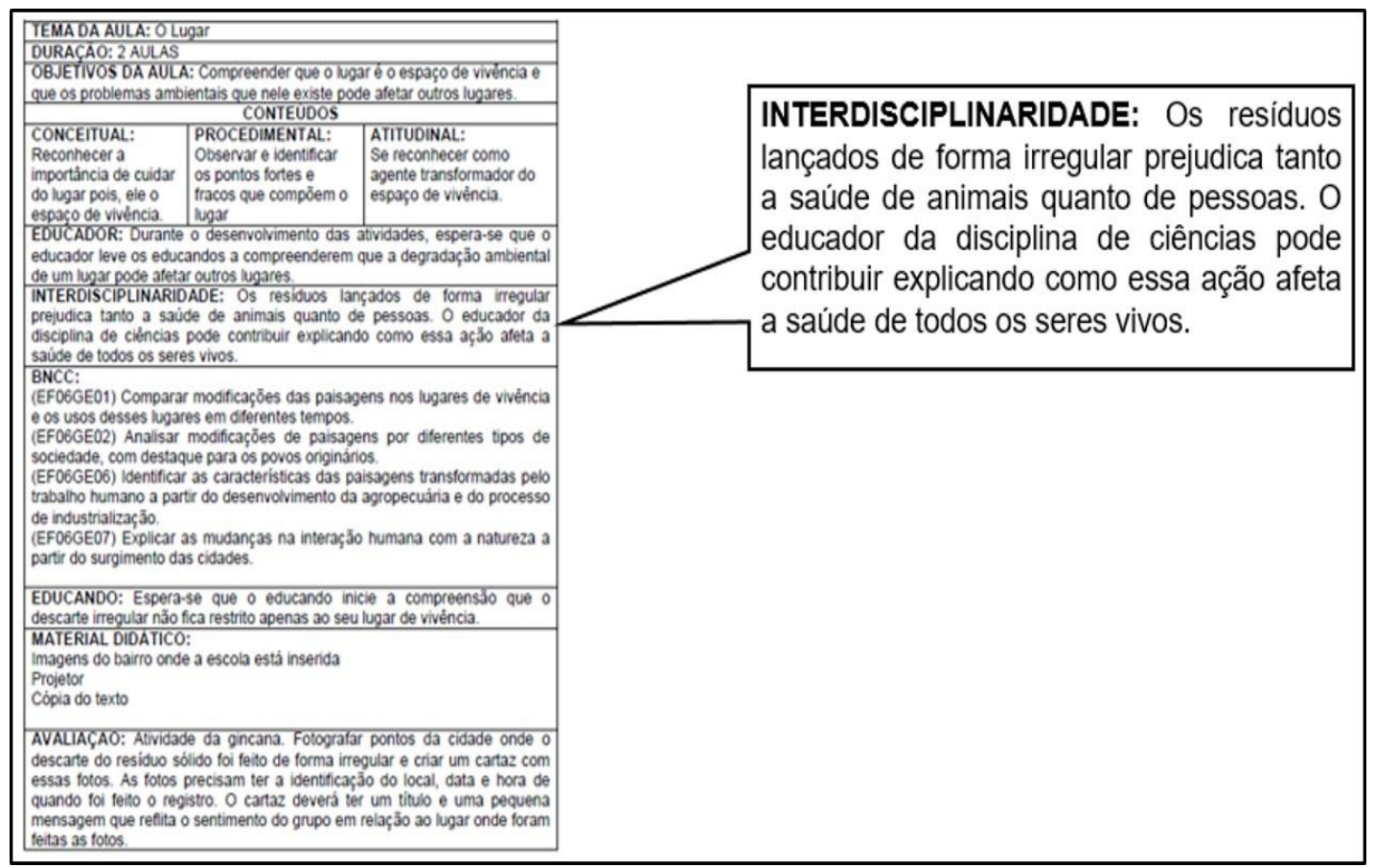

Fonte: Produto Educacional - A Gincana Invadiu a Aula de Geografia, 2020.

Para cada encontro da sequência didática, há o planejamento da aula e o seu desenvolvimento.

O desenvolvimento das aulas ocorrerá dentro do espaço escolar e fora dele da seguinte forma: No primeiro, terceiro e quinto encontro todas as atividades serão realizadas dentro da sala de aula, onde através de uma aula dialogada e análise de textos e imagens, os temas serão trabalhados. $O$ segundo encontro se desenvolverá tanto dentro da sala de aula quanto fora do espaço escola. Neste encontro os educandos poderão observar e analisar uma paisagem em movimento quando estiverem fora do espaço escola. De volta à sala de aula, darão continuidade ao estudo iniciado na observação da paisagem. O quarto encontro ocorrerá fora da escola, onde os educandos deverão realizar duas visitas de campo, sendo uma ao aterro sanitário do município e a outra em uma cooperativa de reciclagem. E finalmente no sexto encontro haverá o encerramento da gincana. 


\section{Validação do Produto}

Após finalizar o produto, ele foi submetido a validação. O produto foi disponibilizado para educadores de diferentes áreas, junto com um questionário a ser respondido. Tanto a gincana quanto o questionário foram disponibilizados através de e-mail e por aplicativo de mensagens instantâneas para 50 educadores. O material ficou disponível para análise de 20 de abril a 15 de maio de 2020, ao final desse período foi possível obter a resposta de 17 educadores.

Foi solicitado que os educadores avaliassem se o produto era adequado para o público ao qual se destina, se o tempo destinado as atividades eram suficientes, e se ele poderia ser aplicado em outras escolas. Além dessas questões também foram solicitados que analisassem se o produto estava de acordo com os critérios estabelecidos pela Coordenação de Aperfeiçoamento de Pessoal de Nível Superior - Capes (BRASIL, 2019). Os critérios analisados foram:

- Aderência: os conteúdos trabalhados são abordados no $6^{\circ}$ ano e podem ser relacionados a questão ambiental?

- Impacto: O produto pode proporcionar alguma mudança de atitude em relação ao descarte dos resíduos sólidos?

- Aplicabilidade: o produto é de fácil aplicação e compreensão?

- Inovação: O produto analisado rompe com metodologias tradicionais?

- Complexidade: O produto envolve diferentes atores? Envolve diferentes conhecimentos?

Todos os educadores que responderam ao questionário lecionam na rede pública, porém $94 \%$ lecionam apenas na rede pública e $6 \%$ atuam tanto da rede pública quanto na privada. A maior parte dos educadores ministram suas aulas nas turmas dos anos finais do ensino fundamental.

Ao serem perguntados se o conteúdo do produto educacional estava de acordo para o público o qual se destina e se ele poderia ser aplicado em outras escolas, todos os educadores responderam que sim. Em relação ao tempo de aulas, duas aulas semanais, apenas um educador relatou que o tempo não era suficiente para a realização das atividades propostas para serem desenvolvidas durante a aula.

Em relação aos critérios estabelecidos pela Capes de aderência, impacto e aplicabilidade, todos os educadores responderam que sim. Nos critérios sobre inovação e complexidade $94,1 \%$ dos participantes responderam de forma afirmativa, os demais responderam que não. No questionário, havia um espaço para os educadores colocarem suas observações, porém os educadores que responderam que nos critérios inovação e complexidade, 0 trabalho não atendia os critérios da Capes não especificaram o motivo deixando o espaço em branco.

revista brasileira educação ambiental 


\section{Conclusões}

No Brasil, recentemente foi criada a Política Nacional dos Resíduos Sólidos, instituída pela lei ํo 12.305/10. Neste documento estão previstas ações que visam a diminuição da geração dos resíduos sólidos, assim como sua destinação e eliminação dos lixões. O plano apresenta a proposta de um consumo sustentável, uma vez que visa o aumento da reciclagem, sendo destinado ao descarte no ambiente, de forma segura, tudo aquilo que não pode ser reciclado ou reutilizado.

Para que haja um consumo sustentável e a destinação correta dos resíduos sólidos é necessário que se invista em Educação Ambiental. O produto desenvolvido visa atender essa necessidade.

O desenvolvimento de práticas ambientais nas escolas, geralmente, é desafiador, pois envolve mudança de hábitos e de valores. Geralmente temas relacionados a Educação Ambiental são trabalhados apenas durante a semana do meio ambiente, são poucas as escolas que conseguem vivenciar a Educação Ambiental de forma contínua.

No dia a dia escolar, normalmente é destinado pouco tempo para abordar os temas relacionados à temática ambiental. $\mathrm{O}$ problema se torna maior nos anos finais do ensino fundamental, pois são várias disciplinas, para os educandos administrarem, com educadores diferentes que muitas vezes lecionam em mais de uma escola, dificultando assim o desenvolvimento de um trabalho em conjunto. Diante deste cenário, buscou-se uma forma de trabalhar a Educação Ambiental nas aulas de geografia de maneira que os educandos se sensibilizem em relação a importância do descarte correto dos resíduos sólidos.

O produto educacional "A gincana invadiu a aula de geografia" surge como uma ferramenta para trabalhar os resíduos sólidos durante as aulas de geografia, levando os educandos a pensarem sobre suas ações no ambiente. A validação da gincana realizada por educadores serviu para verificar sua eficácia na sensibilização e formação de educandos mais responsáveis com as questões ambientais.

De forma lúdica, mas sem deixar de lado todos os conceitos que precisam ser compreendidos pelos educandos, espera-se que as aulas de geografia possam contribuir para a construção de uma sociedade mais responsável em relação as suas ações sobre o espaço geográfico.

Agradecimentos: À escola campo de pesquisa, à Universidade Federal de Pernambuco e ao Programa de Pós Graduação em Rede Nacional para o Ensino das Ciências Ambientais. 


\section{Referências}

ANDRADE, A.S. Gincana sobre resíduos sólidos: a interação entre a geografia e a Educação Ambiental. 2020. Dissertação (Mestrado em Ensino das Ciências Ambientais) - Universidade Federal de Pernambuco, Recife, 2020. Disponível em: https://repositorio.ufpe.br/handle/123456789/39009.

BRANCO, A.R.M.C; MOUTINHO, P.E.C. O lúdico no ensino de física: o uso de gincana envolvendo experimentos físicos como método de ensino. Caderno de Física da UEFS, v. 13, n. 2, p. 2201.1-2201.8, 2015.

BRANCO, E.P.; ROYER, M.R.; BRANCO, A.B.G. A Abordagem da Educação Ambiental nos PCNs, Nas DCNs e na BNCC. Nuances: estudos sobre educação, Presidente Prudente - SP, v. 29, n. 1, p.185-203, Jan./Abr., 2018.

BRASIL. Ministério da Educação - CAPES. Produção Técnica: Grupo de trabalho. Brasilia: CAPES, 2019. Disponível em:

$<$ https://www.capes.gov.br/images/novo portal/documentos/DAV/avaliacao/100 62019 Produ\%C3\%A7\%C3\%A30-T\%C3\%A9cnica.pdf>. Acesso em: 07 set. 2020.

BRASIL. [Constituição (1988)]. Constituição da República Federativa do Brasil. Brasília, DF: Presidência da República. Disponível em: $<$ http://www.planalto.gov.br/ccivil 03/constituicao/constituicao.htm>. Acesso em: 14 jul. 2019.

BRASIL. Lei no 12.305, de 2 de agosto de 2010. Institui a Política nacional de Resíduos Sólidos. Brasília, DF. 2010. Disponível em: <http://www.planalto.gov.br/ccivil 03/ ato2007-2010/2010/lei//12305.htm>. Acesso em: 20 dez. 2019.

CASCINO, F. Educação Ambiental: princípios, história, formação de professores. 3 ed. São Paulo: Senac São Paulo, 2003.

CÂMARA, V.O.F. A importância da Educação Ambiental lúdica: Abordagens e reflexões para a construção do conhecimento infantil. Revista Brasileira de Educação Ambiental, v. 12, nº 4, p. 60-75, 2017.

CAVALCANTI, L.S. Geografia e práticas de ensino. Goiânia: Alternativa, 2002.

CRISOSTIMO, A.L. Educação Ambiental, reciclagem de resíduos sólidos e responsabilidade social: formação de educadores ambientais. Revista Conexão UEPG, v. 7, n. 1, p. 88-95, 2011.

KIMURA, S. Geografia no ensino básico: questões e propostas. 2 ed. São Paulo: Contexto, 2010.

LAYRARGUES, P.P. O cinismo da reciclagem: o significado ideológico da reciclagem da lata de alumínio e suas implicações para a Educação Ambiental. In: LOUREIRO, C.F.B.; LAYRARGUES, P.P.; CASTRO, R.S. (orgs.). Educação Ambiental: repensando o espaço da cidadania. 5 ed. São Paulo: Cortez, 2011. p. 185-225.

revista brasileira educação ambiental 
PUNTEL, G. A. A paisagem no ensino da geografia. Ágora, Santa Cruz do Sul, v. 13, n. 1, p. 283-298, jan./jun. 2007.

SANTOS, A.; COSTA, V.S.O.; SANTOS, T.G. Diagnóstico da gestão dos resíduos sólidos em duas unidades escolares. Revista Brasileira de Educação Ambiental, v. 14, n 4: 25-39, 2019.

SCARLATO, F. C.; PONTIN, J. A. Do Nicho ao Lixo: ambiente, sociedade e educação. São Paulo: Atual, 1992.

SILVA, M.M; SOUZA, M.M. Educação Ambiental e suas Práticas Interdisciplinares. In: FRADE, E.G.; BORÉM, R.A.T. (org). Educação Ambiental no Contexto Escolar por Intermédio do Desenvolvimento de Projetos Interdisciplinares e Transdisciplinares. Lavras: UFLA, 2015. p. 305-332. Disponível em: $<$ http://repositorio.ufla.br/bitstream/1/10508/1/LIVRO Educacaão\%20ambiental\% 20no\%20contexto\%20escolar\%20por\%20intermédio\%20do\%20desenvolviment 0\%20de\%20projetos\%20interdisciplinares\%20e\%20transdisciplinares.pdf>. Acesso em: 15 jul. 2019.

VERRI, J. B.; ENDLICH, A. A utilização de jogos aplicados no ensino de Geografia. Revista Percurso, v. 1, n. 1, p. 65-83, 2009. 